\title{
Recovery of Alumina from Electroslag- Remelting of Ti-Bearing Blast Furnace Slag
}

\author{
Songli Liu \\ Resources and Environmental Engineering College of \\ Panzhihua University \\ Materials Science and Engineering College of Xihua \\ University \\ Panzhihua of SiChuan Province, China \\ e-mail: pzhlsll@163.com
}

\section{Li Cao}

Resources and Environmental Engineering College of Panzhihua University

Materials Science and Engineering College of Xihua University

Panzhihua of SiChuan Province, China

\author{
Kuisong Zhu \\ Resources and Environmental Engineering College of \\ Panzhihua University \\ Panzhihua of SiChuan Province, China
}

\author{
Junyi Xiang \\ Resources and Environmental Engineering College of \\ Panzhihua University \\ Materials Science and Engineering College of Xihua \\ University \\ Panzhihua of SiChuan Province, China \\ Pan Huang \\ Resources and Environmental Engineering College of \\ Panzhihua University \\ Materials Science and Engineering College of Xihua \\ University \\ Panzhihua of SiChuan Province, China
}

\begin{abstract}
The recovery of alumina from electroslagremelting of Ti-bearing blast furnace slag has been investigated by Bayer process, XRD methods. The effects of $\mathrm{NaOH}$ concentration, ratio of liquid to solid, leaching time and temperature, particle size, precipitating time and temperature, calcining temperature and time were investigated. With leaching, filtering, precipitating and calcining, alumina recovery of 75.56 pct was obtained under the conditions of $\mathrm{NaOH}$ concentration of $260 \mathrm{~g} / \mathrm{l}$, ratio of liquid to solid of $5: 1$, particle size of 85 pct passing $0.074 \mathrm{~mm}$, leaching at $373 \mathrm{~K}\left(100^{\circ} \mathrm{C}\right)$ for 160 minutes , precipitating at $313 \mathrm{~K}\left(40^{\circ} \mathrm{C}\right)$ for 35 minutes and Calcining at $1473 \mathrm{~K}$ $\left(1200^{\circ} \mathrm{C}\right)$ for 3 hours.
\end{abstract}

Keywords- Alumina; Blast furnace slag; Bayer process; Electroslag-remelting;Recovery

\section{INTRODUCTION}

Vanadium-titanium-magnetite concentrate is composite ore containing iron, vanadium and titanium, in addition to many other valuable metals (such as $\mathrm{Sc}, \mathrm{Cr}, \mathrm{Ga}, \mathrm{Co}$, etc.). The current process of blast furnace, converter vrecovering and titanium concentrates beneficiation for this kind of mine only makes use of $68 \%$ iron, $47 \%$ vanadium and $15 \%$ titanium[1], which produces a large amount of blast furnace slag containing $22-25 \% \mathrm{TiO}_{2}$. This slag has already accumulated 50 million tons so far, and it is still increasing at a rate of 3 million tons per year[2], resulting in a waste of resources and environment pollution. Therefore, how to recover these Ti-bearing blast furnace slag economically is very significant.

Several studies[3-10] on comprehensive utilisation of Ti-bearing blast furnace slag have been carried out in China from the 1960s. Many of the programs can be divided into two categories: the one is the technology of non-extraction titanium. Using this technique the blast furnace slag containing titanium is directly produced into the building materials or other products. The other is to extract titanium and other valuable components through the metallurgical process [11]. Using aluminothermy process, $\mathrm{Al}-\mathrm{Si}-\mathrm{Ti}$ alloy was obtained as the reduction reagent for waste aluminum. $\mathrm{TiO}_{2}$ and $\mathrm{SiO}_{2}$ in the blast furnace slag were reduced in an electroslag-remelting furnace. Since most of silicon and titanium were replaced by aluminum, Ti-bearing blast furnace slag turned into Albearing slag. Fortunately, when the molten slag was carefully treated in a slag ladle after it effused from the electroslag remelting furnace, most alumina in slag could be settled and separated. Thus, the Al-bearing slag became the raw material instead of waste product. The purpose of the present research is to study the settlement behavior of alumina in the slag. Additionally, it may provide a useful method for separating alumina from Al-bearing slag . 


\section{EXPERIMENTAL}

\section{A. Materials}

Ti-bearing blast furnace slag used in this works were provided by mill of China iron and steel company. Tibearing blast furnace slag and waste aluminum were injected into an electroslag remelting furnace. After reducing for $10 \mathrm{~min}$, the molten slag was slowly cooled down at a cooling rate of $3-5 \mathrm{~K} / \mathrm{min}$ for about $4 \mathrm{~h}$. The slag obtained after these treatments was called Al-bearing slag. The bottom Al-bearing slag was crushed and the Al-Si-Ti droplets were taken out by magnetic separation for weighing. Table 1 indicated the compositions of Tibearing blast furnace slag and Al-bearing slag.

Table 1 Chemical composition of slag, wt-(\%)

J'i-bearing slag
$\mathrm{Al}_{2} \mathrm{O}_{3}$
20.23
22.19
24.25

$\begin{array}{lll}(\mathrm{aO}) & \mathrm{SiO}_{2} & \mathrm{Al}_{2} \mathrm{O}_{3} \\ 29.5 & 5.64 & 48.22 \\ 29.6 & 3.16 & 53.19 \\ 29.65 & 1.99 & 57.66\end{array}$

\section{B. Alumina recovery procedures}

Three procedures were applied to recover alumina from Al-bearing slag: (i) leaching of the aluminium content of Al-bearing slag in the form of soluble sodium aluminate, (ii) transformation of the aluminium content of sodium aluminate into a precipitation, and (iii) filtration, washing, drying and calcination of the precipitates.

Al-bearing slags were leached in a glass beaker $(0.5 \mathrm{dm} 3)$ heated in an isothermal temperature water bath, equipped with a mechanical stirrer and a temperature controller. In each batch, $50 \mathrm{~g}$ of Al-bearing slags (dry weight, precision $0.1 \mathrm{mg}$ ) were added into an aqueous $\mathrm{NaOH}$ solution of the required concentration and volume at the required temperature. A mechanical glass stirrer was operated at a speed of $350 \mathrm{rpm}$.During stirring, lime $(\mathrm{CaO})$ for desilication purposes was added $(0.3 \%$ of the amount of Al-bearing sla), and sufficient water was subsequently added to maintain the total volume constant. When the leaching process was finished, solution and residues were separated by filtering under vacuum, and washed thoroughly with distilled water until a constant filtrate volume was obtained. The collected filtrate was subjected to chemical analysis.

A $1 \mathrm{dm}^{3}$ portion of sodium aluminate solution $\left(130 \mathrm{~g} \cdot \mathrm{dm}^{-3}\right)$ was mixed with freshly prepared aluminium hydroxide gel in a $2 \mathrm{dm}^{3}$ glass beaker. The content of $\mathrm{Al}_{2} \mathrm{O}_{3}$ in the added gel was $42 \mathrm{~g}$, which was equivalent to about $40 \%$ of the $\mathrm{Al}_{2} \mathrm{O}_{3}$ content of the aluminate solution. The mixture was stirred for a few minutes and ensured homogeneity, then a stream of air was passed throughout via a diaphragm pump for $20 \mathrm{~h}$ at $30^{\circ} \mathrm{C}$. Subsequently, the precipitate was filtered, washed and dried. Calcination of the dried materials was conducted in a static atmosphere of air at various temperatures $\left(\mathrm{Tc}=200-1200^{\circ} \mathrm{C}\right)$ for $3 \mathrm{~h}$, using a temperature controlled muffle furnace. The collected products were subjected to XRD and chemical analysis.

\section{RESULTS AND DISCUSSION}

\section{A. Effect of $\mathrm{NaOH}$ concentration on the recovery of alumina}

Figure 1 shows $\mathrm{NaOH}$ concentration on the recovery of alumina at $373 \mathrm{~K}\left(100^{\circ} \mathrm{C}\right)$ for 160 minutes by keeping a ratio of liquid to solid of 5:1 and a particle size of 85 pct
Al-hearing slag

$\begin{array}{lllll}\mathrm{VgO} & \mathrm{MnO}_{2} & \mathrm{leO} & \mathrm{IiO}_{2} & \mathrm{Ii}_{2} \mathrm{O}_{3} \\ 8.06 & 0.103 & 1.03 & 2.98 & 1.05 \\ 8.31 & 0.09 & 0.92 & 1.13 & 1.17 \\ 8.02 & 0.102 & 0.89 & 0.52 & 1.29\end{array}$

passing $0.074 \mathrm{~mm}$ sieve. It is found that the recovery of alumina increases evidently when $\mathrm{NaOH}$ concentration increases from 100 to $260 \mathrm{~g} / \mathrm{l}$. Increasing $\mathrm{NaOH}$ concentration will help to increase internal diffusion, which leads to the increase of recovering alumina. Figure 1 also illustrates that the recovery of alumina difference between $\mathrm{NaOH}$ concentration of 260 and $300 \mathrm{~g} / \mathrm{l}$ is quite small. It may be explained that as $\mathrm{NaOH}$ concentration continued to increase, the driving forces of diffusion reactions became low above a certain $\mathrm{NaOH}$ concentrate, which led to less effect on the recovery of alumina.

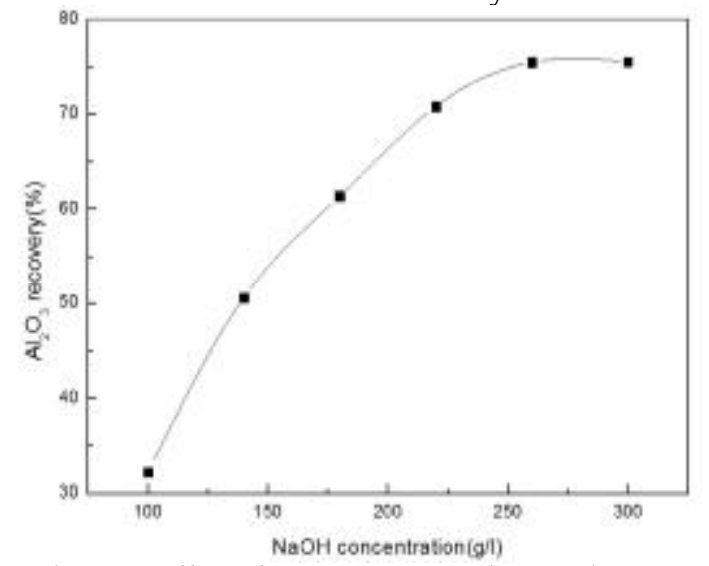

Figure 1. Effect of $\mathrm{NaOH}$ concentration on the recovery of $\mathrm{Al}_{2} \mathrm{O}_{3}$

\section{B. Effect of ratio of liquid to solid on the recovery of alumina}

The effect of ratio of liquid to solid on the recovery of alumina was studied at $\mathrm{NaOH}$ concentration of $260 \mathrm{~g} / \mathrm{l}$, particle size of 85 pct passing $0.074 \mathrm{~mm}$, and leaching at $373 \mathrm{~K}\left(100^{\circ} \mathrm{C}\right)$ for 160 minutes. As shown in Figure 2, it is clear that the recovery of alumina increases significantly when increasing ratio of liquid to solid in the initial stage(the carbon/ore ratio from 2.0 to 5.0) and then almost levels off. It indicates that an effective increase of the recovery of alumina can be achieved by increasing the ratio of liquid to solid. With the increase of ratio of liquid to solid, the contacting area between solution and particles increases, which accelerates the reaction of particles and $\mathrm{NaOH}$ solution. 


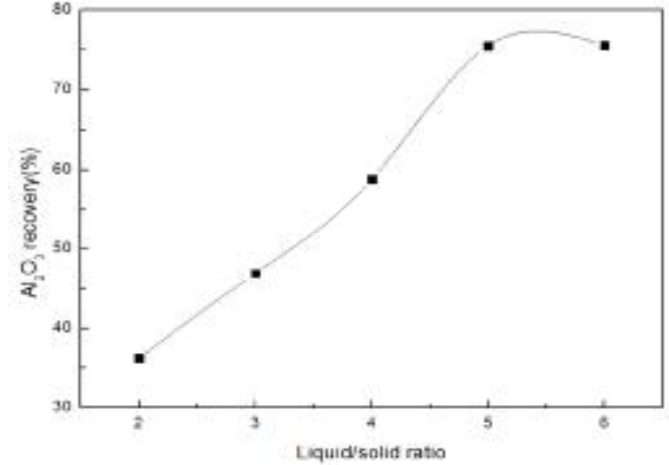

Figure 2. Effect of ratio of liquid to solid on the recovery of $\mathrm{Al}_{2} \mathrm{O}_{3}$

C. Effect of time (tm) and temperature (Tp) in leaching on the recovery of alumina.

The effect of leaching time (tm) on the recovery of alumina at different leaching temperature (Tp) are performed in Figure 3. It is found that a value of $75 \%$ recovery was obtained at $100^{\circ} \mathrm{C}$, as compared with 65 and $45 \%$ at 90 and $80^{\circ} \mathrm{C}$, respectively. Figure 3 also shows the initial high rate of leaching to slow down markedly after the elapse of $160 \mathrm{~min}$ of leaching, regardless of the temperature applied.

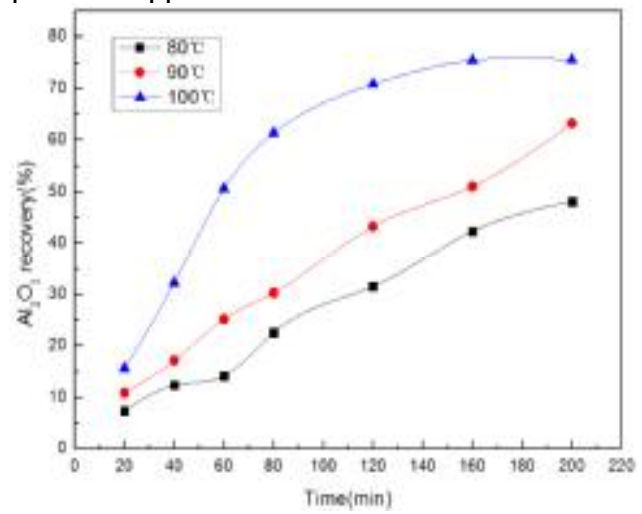

Figure 3. Effect of time $\left(t_{m}\right)$ and temperature $\left(T_{p}\right)$ in leaching on the recovery of $\mathrm{Al}_{2} \mathrm{O}_{3}$

\section{Effect of particle size on the recovery of alumina}

The effect of particle size on the recovery of alumina was examined under the conditions of $\mathrm{NaOH}$ concentration of $260 \mathrm{~g} / 1$, ratio of liquid to solid of 5:1, and leaching at $373 \mathrm{~K}\left(100^{\circ} \mathrm{C}\right)$ for 160 minutes. As shown in Figure 4, It can be seen that by increasing the particle size of the Albearing slags, the recovery of $\mathrm{Al}_{2} \mathrm{O}_{3}$ increased. However, the $\mathrm{Al}_{2} \mathrm{O}_{3}$ recovery is still lower than 80 even though 95 pct of the particles are passing $0.074 \mathrm{~mm}$ sieve. The reason is that some impurities of the alumina do not dissolve in a $\mathrm{NaOH}$ solution.

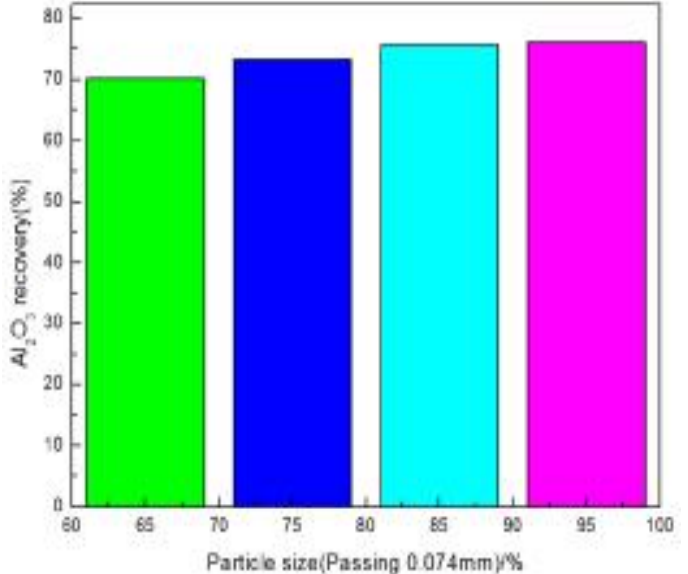

Figure 4. Effect of particle size on the recovery of $\mathrm{Al}_{2} \mathrm{O}_{3}$

E. Effect of time (tm) and temperature (Tp) in precipitating on the recovery of alumina

The effect of precipitating time (tm) on the recovery of alumina at different leaching temperature (Tp) are performed in Figure 5. It is found that all the curves of alumina recovery show a similar trend in just the slope at temperature from 40 to $70^{\circ} \mathrm{C}$ region. The recovery of alumina decreases evidently when precipitating temperature increases from 40 to $70^{\circ} \mathrm{C}$.The alumina recovery at a given temperature increases with the increase of precipitating time, decreases when the time is above $35 \mathrm{~min}$.

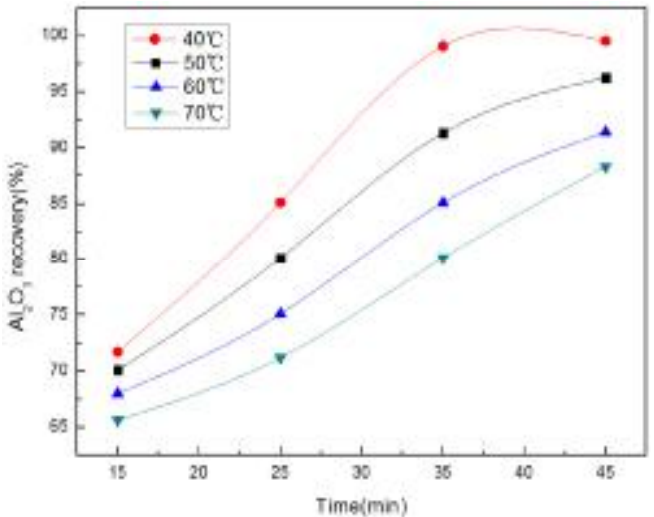

Figure 5. Effect of time $\left(\mathrm{t}_{\mathrm{m}}\right)$ and temperature $\left(\mathrm{T}_{\mathrm{p}}\right)$ in precipitating on the recovery of $\mathrm{Al}_{2} \mathrm{O}_{3}$

\section{F. XRD analysis of calcined alumina}

Figures 6 illustrates x-ray analysis of Al-bearing slag and product. From which it is clear that the main phase of Al-bearing slag is $2 \mathrm{CaO} \cdot \mathrm{Al}_{2} \mathrm{O}_{3} \cdot \mathrm{SiO}_{2}, 12 \mathrm{CaO} \cdot 7 \mathrm{Al}_{2} \mathrm{O}_{3}$, $\mathrm{CaO} \cdot \mathrm{Al}_{2} \mathrm{O}_{3}, \mathrm{CaO} \cdot \mathrm{SiO}_{2}$. By leaching, precipitating and calcination, alumina is produced. In addition, some impurities have remained unreacted in the alumina, and the utilization of alumina will be studied in further research. 


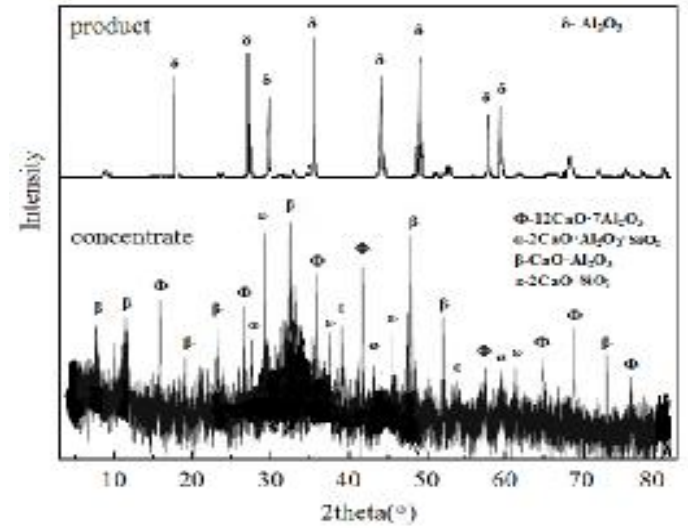

Figure 6. XRD results of Al-bearing slag and product

\section{CONCLUSIONS}

In this study, recovery of alumina from electroslagremelting of Ti-bearing blast furnace slag was investigated. The experiments prove that recovering alumina from Albearing slag by the Bayer process is an effective method. Alumina and other impurities were separated effectively after leaching and filtering. The results show that alumina recovery of 75.56 pct was obtained under the conditions of $\mathrm{NaOH}$ concentration of $260 \mathrm{~g} / \mathrm{l}$, ratio of liquid to solid of 5:1, particle size of 85 pct passing $0.074 \mathrm{~mm}$, leaching at $373 \mathrm{~K}\left(100^{\circ} \mathrm{C}\right)$ for 160 minutes, precipitating at $313 \mathrm{~K}$ $\left(40^{\circ} \mathrm{C}\right)$ for 35 minutes and Calcining at $1473 \mathrm{~K}\left(1200^{\circ} \mathrm{C}\right)$ for 3 hours.

\section{ACKNOWLEDGMENT}

This research is supported by SiChuan province Natural Science Foundation (2010JY0112) and Innovation Program of Panzhihua Municipal Science Technology Commission (2010CY-G-9).

\section{REFERENCES}

[1] Jun Deng, Xun Xue, Guogong Liu: Current situation and development of comprehensive utilization of vanadium-bearing titanomagnetite at PanGang. submitted to Journal of Materials and Metallurgy, 6(2),pp.83-86,2007.

[2] Mingyu Wang:Separation of iron droplets from titania bearing slag. submitted to Journal of iron and steel research,international , 15(1), pp45-48,2008.

[3] Xinghua $\mathrm{Li}$, Jingtao $\mathrm{Pu}$ : The latest developments of integrated utilization on Panzhihua high titanium-bearing BF slag . Iron Steel Vanadium Titanium,32(2),pp10-14,2011.

[4] [4] Qingqiang Weng: High Ti-beard slag comprehensive utilization out line and forecast. volume 31 of Progress in Sichuan Metallurgy, chapter,31(6),pp40-42,2009.

[5] Tiechui Yuan, Honggui Liu: Preparation of rich-titanium materials from blast furnace slag containing titanium . submitted to Journal of Hunan Nonferrous Metal, 25(4),pp38-40,2009.

[6] Wengxin Zhang, Zhencai Li: Study on the core-loss trend and distribution of Pan Gang's blasturnace. submitted to Journal of chongqing college of iron and steel technology,14(2), pp5,1999.

[7] Sijia Wang, Yue Zhang, Xiangxin Xue, et al:Recovery of titanium form titanium-bearing blast furnace slag by ammonium sulfate melting method, submitted to Journal of CIESC journal,63(3),pp991-995,2012.

[8] Xinghua Li, Xuesong Wang, Zhilu Liu, et al: The new direction of comprehensive utilization of high Titanium-bearing slag. submitted to Journal of Iron Steel Vanadium Titanium, 12(3), pp10-16,2009.

[9] Mingyu Wang,Xuewen Wang,Yuehui He, et al: Isothermal precipitation and growth process of perovskite phase in oxidized titanium bearing slag. submitted to Transaction of Nonferrous Metals Society of China,18(3),pp459-462,2008.

[10] Xiaohua Liu, Zhitong Sui: Leaching of Ti-bearing blast furnace slag by pressuring. submitted to The Chinese Journal of Nonferrous Metal, 12(6),pp1281-1284,2002.

[11] Huadong Liao: Study on separating titanium form the high titanium-bearing blast furnace slag of Pangang. Chong Qing: Chong Qing University, 2006. 